\title{
The use of carbon dioxide laser in selected surgical cases in patients on anticoagulant therapy
}

\author{
Michael SG Bell MD FRCS FACS, S Shanhrokhi Ebrahimipour BSc \\ Division of Plastic Surgery, Ottawa Hospital, Civic Campus, Ottawa, Ontario
}

MSG Bell, S Ebrahimipour. The use of the carbon dioxide laser in selected surgical cases in patients on anticoagulant therapy. Can J Plast Surg 1999; 7(5):237-239.

Postoperative bleeding is encountered with much greater frequency in patients with congenital coagulation defects and in patients on warfarin therapy. Anticoagulation management before and after elective surgery is well documented. Cessation of anticoagulation therapy is required before elective surgery, except in the most minor dermatological surgical procedures such as Mohs surgery or simple excisions. This may pose significant economic consequences, especially when hospital admission for several days and substitution of heparin for warfarin under close monitoring is required. Use of a carbon dioxide laser, which considerably reduces intraoperative bleeding and postoperative oozing, is proposed as an alternative approach to selected surgical procedures.

Key Words: Anticoagulant therapy; Carbon dioxide laser; Factor 8.

L'utilisation du laser au gaz carbonique dans certains cas chirurgicaux chez des patients recevant un traitement anticoagulant

RÉSUMÉ : Les saignements postopératoires sont plus fréquemment observés chez des patients accusant une coagulopathie d'origine congénitale et chez ceux qui sont traités avec de la warfarine. La prise en charge de l'anticoagulation avant et après une chirurgie élective est bien documentée. On doit arrêter le traitement anticoagulant avant une chirurgie élective, sauf dans le cas des interventions chirurgicales les plus mineures en dermatologie telles une chirurgie de Mohs ou des exérèses simples. Ceci peut avoir des conséquences économiques importantes, en particulier lorsqu'une hospitalisation de plusieurs jours et que la substitution de l'héparine à la warfarine sous étroite surveillance sont nécessaires. L'utilisation du laser au gaz carbonique, qui réduit considérablement les saignements peropératoires et les suintements postopératoires, est proposée comme solution de remplacement dans certaines interventions chirurgicales.

$\mathrm{T}$ This paper reports a small series of surgical procedures using the Luxar carbon dioxide laser, done in patients with mild coagulopathies.

The first patient had a bilateral carpal tunnel syndrome, and Von Willebrand's disease. His factor 8 was known to be about $20 \%$ of normal, and assurance was given by the hematologist that the patient could safely undergo a carpal tunnel release without supplementary factor 8 .

His right carpal tunnel release was carried out in the con-

Correspondence and reprints: Dr M Bell, Ottawa Hospital, Civic Campus, 1053 Carling Avenue, Ottawa, Ontario K1Y 4E9. Telephone 613-739-5424, fax 613-739-7168, e-mail msgbell@cyberus.ca ventional manner under local anesthesia, with no noted abnormal bleeding. A compression dressing was applied; however, that evening he noted that his fingers were becoming somewhat congested and blue, and there was some breakthrough bleeding on the dressing despite an adequate amount of padding. He presented to the emergency department with persistent oozing from the wound. There was, fortunately no hematoma, and he was referred to his hematologist, who gave the patient factor 8 . The bleeding stopped immediately, and he carried on to have an uneventful postoperative course. A rather remarkable amount of bruising was present up to the mid-forearm, but there was only a modest degree of swelling, and his symptoms of pain and numbness were relieved. His abductor pollicus brevis strength increased progressively afterwards, and he made a full recovery. This same patient 
subsequently developed painful triggering and locking in his thumb, which was resistant to three cortisone injections. It was felt that a trigger thumb release could be quite safely carried out using the carbon dioxide laser, with its known properties of hemostasis in soft tissue incisions $(1,2)$. This would avoid the necessity of the factor 8 administration. This procedure was carried out using the Luxar laser, at a $10 \mathrm{~W}$ setting. Although he had no bruising or swelling, he did have a stitch abscess in the incision line that was felt to be unrelated to the use of the laser. His thumb recovered uneventfully.

Subsequently the patient went on to develop quite progressive and severe symptoms of a left carpal tunnel syndrome, with nocturnal pain disturbing his sleep pattern and associated with paresthesis and hypoesthesia even during the day. Because the use of carbon dioxide laser in carpal tunnel surgery has been reported by several investigators with good results $(2,3,4)$, his left carpal tunnel release was carried out using the carbon dioxide laser set at $15 \mathrm{~W}$. The nerve was released without difficulty, and he recovered with minimal swelling and discolouration in this hand. No factor 8 was required. This was quite a dramatic change from a previous carpal tunnel release procedure in his right hand when no laser was used and that resulted in postoperative bleeding and the administration of factor 8 .

Prompted by this one case we have subsequently carried out 12 more carpal tunnel releases in patients on warfarin. These were all patients who had artificial heart valves, where it was felt by their cardiologist that stopping their warfarin for any period of time was contraindicated. It was advised that heparin be administered during an in hospital stay, providing a window during which the surgery could be more safely carried out. In accordance with the literature, the management of patients on anticoagulant therapy requiring surgery involves stopping the oral anticoagulant three to five days preoperatively; substituting intravenous heparin preoperatively; stopping the intravenous heparin 6 to $12 \mathrm{~h}$ preoperatively; restarting intravenous heparin within $6 \mathrm{~h}$ of the completion of the procedure; and resuming oral anticoagulants when the patient is able to drink $(3,5,6)$.

Instead of the above procedure the carbon dioxide laser was used to release their volar carpal ligaments. All procedures were carried out uneventfully, with no increased bruising postoperatively and no complications.

Finally, a Dupuytren's complex excision with an associated painful trigger finger was done, again uneventfully in another patient on warfarin.

In this brief series of patients we have concluded that the laser does provide adequate hemostasis locally in people with mild coagulation abnormalities. It can allow surgery to be done with a reasonable margin of safety and at a lower cost than current conventional approaches, especially when admission to hospital was recommended to administer heparin for patients on warfarin who had artificial heart valves $(7,8)$. In all incisions, a $0.4 \mathrm{~mm}$ cutting head was used on the Luxar laser.
In the carpal tunnel procedures, the final element of the volar carpal ligament, which is bloodless, was incised with a 15 blade to allow insertion of a bent Joseph elevator that had been polished with 600 grit abrasive paper to remove the shine. This protected the underlying median nerve to permit release of all elements of the ligament. The laser was set at P10 at this stage to allow the best cutting control. The flexible cable allows precise manipulation of the laser and is the chief advantage of the Luxar laser over conventional carbon dioxide units.

An elective finger amputation was done in a patient who required anticoagulant therapy for an artificial aortic valve, who presented with severe distal interphalangeal joint pain of her left index finger as result of longstanding gout. Splinting had been attempted with little relief of symptoms. Because fusion of the joint was contraindicated, amputation of her finger was presented to her as an alternative. The amputation was carried out using the carbon dioxide laser with no complications, no bruising and minimal swelling.

Following these successes, and the reports in the literature regarding the effectiveness of carbon dioxide laser in reducing intraoperative edema in blepharoplasty (9), we proceeded to do a functional upper eyelid blepharoplasty in a patient on warfarin with a mechanical mitral valve. He had a major visual field defect from the excess upper lid skin. His international normalized ratio preoperatively was 2.5. The procedure was done with local anesthesia (lidocaine $2 \%$ with adrenalin). A small hematoma was noted immediately on the left side on the withdrawal of the 25 gauge needle. Skin and fat pads were removed with the carbon dioxide laser at a power setting of $5 \mathrm{~W}$ using a $0.4 \mathrm{~mm}$ cutting head. Nine days after surgery the patient had a small crust with slight erythema and swelling on the left upper lid in the incision line. The cause was most likely a chromic suture. When the suture was removed the incision line continued to ooze slowly for $24 \mathrm{~h}$. His international normalized ratio was 3.7 on this day. The incision was still not fully healed after two weeks and a hematoma cavity $8 \mathrm{~mm}$ long by $5 \mathrm{~mm}$ wide was noted. This healed after three weeks.

Despite the problem in this latter case, the complication of delayed healing following bleeding was minor. Indeed, it seems likely that the hematoma originated from the local anesthetic injection.

Trying to do these described procedures by conventional techniques would have caused the patient considerable inconvenience and expense. There is still a risk of bleeding with heparin coverage, during the period of warfarin cessation, and indeed there is a risk of thromboembolism developing during the time of conversion from heparin back to warfarin $(10,11)$.

The modest experience with a carbon dioxide laser suggests that it is reasonable to advocate using this technique in selected circumstances. 


\section{REFERENCES}

1. Arnoff BL. The carbon dioxide laser in head and neck and plastic surgery: Advantages and Disadvantages. In: L Goldman, ed. The Biomedical Laser: Technology and Clinical Applications New York: Springer-Verlag, 1981:239.

2. Bergman RS, Murphy BJ, Foglietti MA. Clinical experience with the $\mathrm{CO}_{2}$ laser during carpal tunnel decompression. Plast Reconstr Surg 1988;81:933-8.

3. Scheiblbrandner W, Stroheker J, Diemath HE. The Use of Laser in Carpal Tunnel Surgery. The 4th Congress of the International Society for Laser Surgery Tokyo, November 23 to 27, 1981.

4. Pariente R, Baiani G, Bucher S. The Use of CO laser in some specific instances of the Hand Surgery, In: Kaplan I, ed. Laser Surgery II. Jerusalem: Academic Press, 1978:104.

5. Kearon C, Hirsh J. Management of anticoagulation before and after elective surgery. N Engl J Med 1997;336:1506-11.

6. Madura JA, Rookstool M, Wease G. The management of patients warfarin therapy undergoing subsequent surgical procedures. Am Surg 1994;60:542-6.

7. Bodnar AG, Hutter AM Jr. Anticoagulation in valvular heart disease preoperatively and postoperatively. Cardiovasc Clin 1984;14:247-64.

8. Papa MZ, Amsterdam E, Schneiderman J, et al. Hemorrhagic complications encountered on a surgical service. A 7 year survey. Am J Surg 1984; 147:378-81.

9. David LM, Sanders G. CO laser blepharoplasty: a comparison to cold steel and electrocautery. J Dermatol Surg Oncol 1987;13:110-4.

10. Goldsmith SM, Leshin B, Owen J. Management of patients taking anticoagulants and platelet inhibitors prior to dermatologic surgery. J Dermatol Surg Oncol 1993;19:578-81.

11. Billingsley EM, Maloney ME. Intraoperative and postoperative bleeding problems in patients taking warfarin, aspirin, and nonsteroidal antiinflammatory agents. A prospective study. Dermatol Surg 1997;23:381-5. 